\title{
THE RELATIONSHIP BETWEEN HEALTH ANXIETY, PERCEIVED STRESS AND SATISFACTION OF PET OWNERS
}

\author{
Mădălina BUDIMIR ${ }^{1}$
}

\begin{abstract}
Introduction: The aim of the study is to see if and in what way pets influence certain aspects of their owners. lives. Methodology: A number of 856 participants filled in the online form, out of which 586 have at least one pet. Results: The results show that there are significant differences between the two groups. Animal owners are less anxious about their health, have a lower perceived stress level and higher life satisfaction than non-owners. Conclusion: Given the results obtained, pets positively influence the life of the owner. This link should be studied in more detail in future research.
\end{abstract}

Key words: human-animal interaction, life satisfaction, perceived stress, pets, anxiety

\section{Introduction}

In the field of health, the effects of animal-assisted therapy (AAT) on patients were studied, and the results were spectacular. Hospitalization produces stress, anxiety, feelings of isolation, depression, regardless of age. Animal-assisted therapy meets the needs of patients by reducing all these conditions (Barchas et al., 2020).

The results were similar both in the case of short interventions of 5 to 20 minutes and in the case of long interventions of more than 20 minutes (Abate, 2011; Waite at al., 2018). This therapy is used to reduce pain, fatigue, depression and anxiety. After animal-assisted therapy sessions, the results showed that in addition to reducing the stress caused by hospitalization, it has beneficial effects on well-being. Paients are more motivated to heal, more relaxed, collaborate more with hospital staff and with family. (Schimtz, et al. 2017; Harper, et al., 2015; Marcus, et al., 2012; Phung, et al., 2017).

Not only animal-assisted therapy brings benefits for people, but also owning pets. In a comparative study conducted by Raghunath and colleagues (2017), they concluded that pet owners are happier, physically healthier and they have lower levels of anxiety and depression.

\footnotetext{
${ }^{1}$ West University of Timisoara,Timisoara, madalina.budimir99@e-uvt.ro corresponding author
} 
In the case of hospitalized patients, an improvement in well-being was observed following family visits with pet. They reported feeling less lonely, anxious or sad. Those who have a companion animal said that they are happy that animal-assisted therapy exists, but they would feel better if they saw their own animal (Barchas et al., 2020). Given the seriousness of many illnesses, ex.cancer, patients need all the support they can get. This can be given besides their partner (Vintila, M., Stefanut, A., Sarbescu, P, 2019; Stefanut, A., Vintila, M, 2019), also by pets, mainly dogs.

The social support that pets represent is considered an important modulator of stress. Put in a stressful laboratory situation, adults reported a lower level of stress when in the company of a dog than if they were alone or with a friend. These results were also obtained due to the fact that the friend can evaluate performance in task, being a source of additional stress, while a dog is a non-evaluative company (Kertes, et al., 2016).

This has also been observed in older people. They have reached a respectable age when they are in the situation of losing loved ones. It feels like they can no longer talk to anyone because of the fear of being judged and ridiculed and the fact that they have a pet, a source of unconditional support, helps them cope more easily with stress and loneliness (Pachana et al., 2011). It can be part of a healthier life style at this age (Eglite, A., Vintila, M., Grinfelde, A., Kantike, I., 2009, Vintila, M., Marklinder, I., Nydahl, M., Istrat, D., Kuglis, A., 2009).

Given that perceived stress is one of the predictors of happiness, González-Ramírez and collaborators (2018), investigated the link between happiness, perceived stress and the human-dog relationship. The results showed that people who reported higher levels of subjective happiness and lower perceived stress, also showed higher values in their relationship with their dog.

Thus, a factor of major importance in peoples' life is represented by the quality of their relationships (Coman, 2018a, p.245), whether they are relationships with humans or animals. However, peoples' level of life satisfaction and happines can also be influenced by the image they have regarding the life they should have, and in this regard, one must take into account the fact that "between images and reality there is a close connection, due to the fact that images reflect the reality, being based on the sensorial information from the external reality and on the information that exists in peoples' minds" (Coman, 2018b).

The human-dog relationship has direct effects on perceived stress, but not on subjective happiness. Thus, happiness is also analysed today in the context of consumer behavior, and in today's society, happiness as an obligation is translated simply through the idea of consumerism (Coman, 2007, p.27) meaning that the more people have, the happier they will be.

More specifically, owners who spend more time with dogs, play together and let their dogs be present in their daily activities, not only have a better relationship, but have a lower level of perceived stress.

The explanation given by the authors is that pets provide social support for owners, and this interaction makes them more relaxed to perceive stress and 
recognize subjective happiness (Swami, V., Khatib, NAM, Vidal-Mollon, J, Vintila, M., Barron, D., Goian, C., Mayoral, O., Toh, EKL, Tudorel, O., Vazirani, S., 2019).

Dog owners reported lower levels of psychosomatic and stress indicators, but also higher levels of health, energy, absence of body pain, social functioning and mental health than non-dog owners. However, there were no significant differences between the two groups in terms of life satisfaction, happiness, physical functioning (González \& Hernández, 2014).

In some studies, such as the one presented above, the relationship between life satisfaction and the possession of a pet is statistically insignificant, while in other studies it is significant. For example, in the research conducted by Bao and Schreer (2016), the results show that pet owners have higher scores on life satisfaction than non-owners, but for the other components of well-being (positive and negative emotions ) no differences were observed.

Studies on life satisfaction have shown that social support is an important factor. The fact that they have good relationships with family and at work can increase the level of life satisfaction. Also, the perceived support from friends has this effect (Connaughton, 2016). Pets can, in a way, be considered as a substitute for human social support, and this should increase life satisfaction.

Thus, a study evaluating the link between pets, physical function, and psychological factors found that people who had pets reported a significantly higher level of perceived and anticipated social support than those who did not own pets (Connaughton, 2016).

Another study (Luhmann \& Kalitzki, 2016) presents both the positive and negative parts of caring for a pet (dog, cat or horse) associated with life satisfaction. Satisfying the need for autonomy, the fact that they experience positive emotions when they are with the pet and the fulfillment of social roles are associated with a higher level of life satisfaction.

On the other hand, the higher financial stress felt due to the pet and the experiencing negative emotions were associated with a lower level of life satisfaction. In certain psychiatric diseases or personality disorders associated with lower levels of life quality and/or life satisfaction owning a pet can increase their level of well-being (Swami, V., Barron, D., Vintila, M., Ong, HS, Tudorel, O., Goian, C, Wong, KY, Toh, EKL.,2021, Barron., D., Vintila, M., Swami, V., 2020).

The purpose of this study is to see if owning a pet improves certain aspects of life. More specifically, we studied a comparison between owners and non-owners of animals on certain aspects related to life: anxiety related to perceived health, life satisfaction and perceived stress.

The hypotheses of the study are:

(1) There will be differences between pet owners and non-owners regarding health anxiety.

(2) Pet owners will have a lower perceived stress level than non-owners.

(3) Pet owners will be more satisfied with life than non-owners. 


\section{Methodology}

\subsection{Participants}

The study had 856 participants, owners and non-owners of pets. Of these, 95.1\% ( $N$ $=815$ ) were female with an average age of 28.63 years. The majority of participants, $68.4 \%(N=586)$ have at least one pet, of which $32.2 \%$ live in the house where they also have a yard, and approximately $67 \%$ in an apartment.

Out of these, $45 \%$ have at least one dog, $21 \%$ have at least one cat. Among pet owners, $41 \%$ walk their animal, and $27.9 \%$ walk it $2-3$ times a day. $45 \%$ of owners perceive their pet as very active (1-3 hours a day), and $51.5 \%$ consider its health to be very good.

\subsection{Instruments}

Health anxiety. To measure health anxiety we used the Health Anxiety Inventory (HAl), the short version. The scale was developed by Warwick and Salkovskis in 1989 and it is based on the cognitive theory of anxiety and hypochondria and has been found to distinguish between patients with hypochondria and non-clinical cases.

The scale has 18 items that are composed each of 4 statements targeting patients suffering from health anxiety, on the one hand, and other anxiety disorders and physically ill patients, on the other hand. The Alpha Cronbach coefficient is .85 which means that the scale has a high internal consistency.

Perceived stress. We used the Perceived Stress Questionnaire (PSQ) developed by Levenstein et al. (1993), a relevant tool in determining the level of perceived stress. The scale contains 30 items, each item having a Likert scale from 1 (Almost never) to 4 (Almost always). The internal consistency was measured with the Alpha Cronbach coefficient (.93), the scale having an excellent level.

Life satisfaction. I used the questionnaire made by Diener (1985), Life Satisfaction Scale (SWLS). The scale is designed from 5 items on a Likert scale from 1 (total disagreement) to 7 (total agreement) to provide an overview of life and measure life satisfaction. The Apha Cronbach coefficient is .84, which represents a high level of internal consistency

\subsection{Procedure}

As procedure, a questionnaire was made in Google Forms which contains the scales specified above and it was distributed online. The participants gave their informed consent. After collecting the data, the participants were divided into two groups: pet owners and non-owners.

\section{Results}


Demographic data

Table 1

\begin{tabular}{|l|l|l|l|l|}
\hline & & & $M$ & $S D$ \\
\hline Age & & & 28,63 & 7,68 \\
\hline Gender & & & $N$ & $\%$ \\
\hline Female & & & & \\
\hline Male & & & 815 & 95,1 \\
\hline Educational level & & 41 & 4,8 \\
\hline high school & & & & \\
\hline secondary & & & 213 & 24,9 \\
\hline university studies & & 32 & 3,7 \\
\hline postgraduate studies & & 414 & 48,3 \\
\hline Others & & 194 & 22,6 \\
\hline Do you have pets? & & 3 & 0,4 \\
\hline Yes & & & 586 & \\
\hline No & & 270 & 68,4 \\
\hline \multicolumn{2}{|l|}{ Type of pets } & & & 31,5 \\
\hline no pets & & 295 & 34,4 \\
\hline Dog & & 181 & 44,5 \\
\hline Cat & & & 21,1 \\
\hline
\end{tabular}

Health anxiety correlates significantly with perceived stress $(r=39, p<.001)$, but also with life satisfaction $(r=-.29, p<.001)$. Perceived stress also correlates significantly with life satisfaction $(r=-.51, p<.001)$. These results support the research approach, ie the observation of the differences between pet owners and non-owners regarding these factors.

Table 2

Descriptive statistics, correlation coefficients and fidelity coefficients for the studied variables

\begin{tabular}{|c|l|l|l|l|l|}
\hline Observed variables & $M$ & $S D$ & 1 & 2 & 3 \\
\hline 1. Heath anxiety & 12.24 & 6.93 & $(.85)$ & & \\
\hline 2. Perceived stress & 59.92 & 13.62 & $.39 * * *$ & $(.93)$ & \\
\hline 3. Life satisfaction & 27.57 & 5.13 & $-.29 * * *$ & $-.51^{* * *}$ & $(.84)$ \\
\hline
\end{tabular}

Note. ${ }^{*} p<.05 ;{ }^{* *} p<.01 ;{ }^{* * *} p<.001$ (bi-directional); $N=856 ; \alpha$ Cronbach Coefficients are present on the main diagonal

To verify the first hypothesis that there are differences between pet owners and non-owners regarding health anxiety we used $T$ tests for independent samples. Pet owners $(N=552)$ have a lower level of health anxiety $(M=10.80, S D=5.36)$ than non-owners $(N=255, M=12.00, S D=5.61)$. This difference is statistically significant, 
$t(805)=2.92, p=.002$. The effect size is small, $d$ Cohen $=.21$.

To see if the second hypothesis is confirmed that animal owners have a lower perceived stress level than non-owners we used $T$ tests for independent samples. Participants $(N=542)$ who have pets have a lower level of perceived stress $(M=56.08, S D=10.24)$ than participants $(N=231)$ who do not have pets $(M=58.80$, $\mathrm{SD}=10,30)$. The differences are statistically significant, $t(771)=3.37, p<.001$. The effect size is small, $d$ Cohen $=.26$.

To see if pet owners are more satisfied with life than non-owners, we used T-tests for independent samples. Participants $(N=570)$ who have at least one pet are more satisfied with their life $(M=28.81, S D=4.17)$ than participants $(N=248)$ who do not have a pet $(M=26.74, S D=4.35)$. This difference is statistically significant, $t(816)=6.43, p<.001$. The effect size is average, $d$ Cohen $=.49$.

Table 3

$T$ test results and descriptive analysis for health anxiety, perceived stress and satisfaction with life depending on owning a pet

\begin{tabular}{|c|c|c|c|c|c|c|c|c|c|}
\hline & \multicolumn{6}{|l|}{ Group } & \multirow[b]{3}{*}{$\mathbf{t}$} & \multirow[b]{3}{*}{ df } & \multirow[b]{3}{*}{$\mathbf{P}$} \\
\hline & \multicolumn{3}{|c|}{ Group with pets } & \multicolumn{3}{|c|}{ Group without pets } & & & \\
\hline & M & SD & $\mathbf{n}$ & M & SD & $\mathbf{n}$ & & & \\
\hline Health anxiety & 10.80 & 5.36 & 552 & 12.00 & 5.61 & 255 & 2.92 & 805 & .002 \\
\hline Perceived stress & 56.08 & 10.24 & 542 & 58.80 & 10.30 & 231 & 3.37 & 771 & .001 \\
\hline Life satisfaction & 28.81 & 4.17 & 570 & 26.74 & 4.35 & 248 & 6.43 & 816 & .001 \\
\hline
\end{tabular}

Note $\mathrm{N}=818$

\section{Discussions}

(1) There will be differences between pet owners and non-owners regarding health anxiety.

The results confirm the first hypothesis of the study. These results are consistent with previous research showing that pets as well as animal-assisted therapy reduce anxiety in general, but especially in hospitalized and chronically ill patients. The relationship between health anxiety and pet ownership has not been directly investigated in the literature, but previous studies found are representative examples that reinforce and support the results of this study.

In some hospitals visits with the patient's pet are allowed. They report a lower level of anxiety, sadness and isolation from these visits. Animal-assisted therapy also helps reduce anxiety, stress, and pain in both adults and hospitalized children (Barchas et al., 2020).

This is possible because animals are seen as sources of support, and when we spend time with them hormones such as dopamine, oxytocin, cortisol are released which lead to these results (Chan \& Rico, 2019). It can also help bonding and improving family relationships in difficult situations (Sirbu, A., Vintila, M., Tisu, L., Stefanut, AM, Tudorel, O., Maguran, B., Toma, RA (2020). 
(2) Pet owners will have a lower perceived stress level than non-owners.

The theory of social support (O'Haire, 2010) can explain the lower level of perceived stress in those who own a pet compared to non-owners. People who do not receive social support feel the effects of stress more and have a lower life satisfaction. The results of this study are consistent with this theory, with pet owners having a lower perceived stress level than non-owners.

This relationship is proven and supported by experiments performed on both adults and children. Kertes (2016) performed two similar experiments. Placed in a stressful situation in the laboratory, both adults and children expressed a decrease in perceived stress in the presence of a dog than in the presence of a friend / parent. The researcher explains that people see in the pet an unconditional and nonevaluative social support. The same results were obtained in another study conducted on the elderly population (Pachana et al., 2011).

(3) Pet owners will be more satisfied with life than non-owners.

The obtained results confirm the hypothesis and are consistent with the theory of social support. According to this theory, pets provide social support and are considered facilitators of human interaction. This theory emphasizes that animals can reduce loneliness and help increase life satisfaction and psychological well-being (O'Haire, 2010).

Also, the results of previous studies were similar. Bao and Schreer (2016) made a comparison between owners and non-owners which shows that people who have a pet are more satisfied with their lives than those who do not. On the other hand, Mháistir (2013) in the research conducted on the elderly population did not find significant differences between owners and non-owners of pets, but differences depending on the type of animal they have.

The explanations given by the authors of these studies are that the former sample was formed predominantly by young people alone, while in the latter one, it was composed of older people who were married or had partners.

These mixed results can also be caused by the different methodological approaches used in the studies, but also by the field in which they are performed. Some studies are conducted by researchers in the field of psychology, others by those specializing in veterinary medicine, for example, and the results may differ (Utz, 2013).

\section{Limitations and future research directions}

One limit is the gender ratio. The sample consisted mainly of women.

Another limitation would be that the relationship between the variables should have been studied in more detail.

It would be more interesting to study the relationship between health anxiety and pet ownership. Also, the inclusion of cat or other pet owners in studies would fill the gap in the literature. 


\section{References}

Abate, S. V., Zucconi, M., \& Boxer, B. A. (2011). Impact of canine-assisted ambulation on hospitalized chronic heart failure patients' ambulation outcomes and satisfaction: a pilot study. Journal of Cardiovascular Nursing, 26(3), 224-230.

Bao, K. J., \& Schreer, G. (2016). Pets and happiness: Examining the association between pet ownership and wellbeing. Anthrozoös, 29(2), 283-296.

Barchas, D., Melaragni, M., Abrahim, H., \& Barchas, E. (2020). The Best Medicine: Personal Pets and Therapy Animals in the Hospital Setting. Critical Care Nursing Clinics, 32(2), 167-190.

Barron, D., Vintila, M., Swami, V., (2020). An assessmnet of the dimensionality of a Roanian translation of the schizotypal personality questionnaire and associations with quality of life, self-esteem and life satisfaction. Schizofrenia Bulletin, 46, 226.

Chan, M. M., \& Rico, G. T. (2019). The "pet effect" in cancer patients: Risks and benefits of human-pet interaction. Critical reviews in oncology/hematology, 143, 56-61.

Coman, C. (2007). Tehnici de negociere. București:CH Beck.

Coman, C. (2018a). Happiness as a resilience resource for the social reproduction of human capital in the private sphere. Economic and Social Development: Book of Proceedings, 241-247.

Coman, C. (2018b). Analiza imaginii și influența Mass media. Image analysis and Mass media influence] Timișoara: Editura de Vest.

Diener, E. D., Emmons, R. A., Larsen, R. J., \& Griffin, S. (1985). The satisfaction with life scale. Journal of personality assessment, 49(1), 71-75.

Eglite, A., Vintila, M., Grinfelde, A., Kanitike, I., (2009), Healthy lifestyle in the elderly's view in Romania and Latvia, Economic Science for Rural Development.

González, M. T., Landero, R., (2011). Differences in perceived stress, mental and physical health, based on the type of human-dog relationship. Rev. Colomb. Psicol. 20, 75-86.

Harper, C. M., Dong, Y., Thornhill, T. S., Wright, J., Ready, J., Brick, G. W., \& Dyer, G. (2015). Can therapy dogs improve pain and satisfaction after total joint arthroplasty? A randomized controlled trial. Clinical Orthopaedics and Related Research, 473(1), 372-379.

Kertes, D. A., Liu, J., Hall, N. J., Hadad, N. A., Wynne, C. D., \& Bhatt, S. S. (2017). Effect of pet dogs on children's perceived stress and cortisol stress response. Social Development, 26(2), 382-401.

Levenstein, S., Prantera, C., Varvo, V., Scribano, M. L., Berto, E., Luzi, C., \& Andreoli, A. (1993). Development of the Perceived Stress Questionnaire: a new tool for psychosomatic research. Journal of psychosomatic research, 37(1), 19-32.

Luhmann, M., \& Kalitzki, A. (2018). How animals contribute to subjective well-being: A comprehensive model of protective and risk factors. The Journal of Positive Psychology, 13(2), 200-214. 
Marcus, D. A., Bernstein, C. D., Constantin, J. M., Kunkel, F. A., Breuer, P., \& Hanlon, R. B. (2012). Animal-assisted therapy at an outpatient pain management clinic. Pain Medicine, 13(1), 45-57.

Mhaistir, G. (2013). Influence of pet ownership on self-esteem, life satisfaction and loneliness among over $65 \mathrm{~s}$ in Ireland. Retrieved from https://esource.dbs.ie/handle/10788/1607

O'Haire, M. (2010). Companion animals and human health: Benefits, challenges, and the road ahead. Journal of Veterinary Behavior, 5(5), 226-234.

Pachana, N. A., Massavelli, B. M., \& Robleda-Gomez, S. (2011). A developmental psychological perspective on the human-animal bond. In The psychology of the human-animal bond (pp. 151-165). Springer, New York, NY.

Phung, A., Joyce, C., Ambutas, S., Browning, M., Fogg, L., Christopher, B. A., \& Flood, S. (2017). Animal-assisted therapy for inpatient adults. Nursing2020, 47(1), 63-66.

Raghunath, D., Rathore, D., Shukla, H., Bilaye, N., Sahu, N., Gupta, N., \& Sharma, K. (2017). A Comparative Study of Pet Owners and Non-Pet Owners to find out the Difference between their Physical, Mental, and Social Well-Being. Annals of Community Health, 5(3), 9-13.

Salkovskis, P. M., Rimes, K. A., Warwick, H. M. C., \& Clark, D. M. (2002). The Health Anxiety Inventory: development and validation of scales for the measurement of health anxiety and hypochondriasis. Psychological medicine, 32(5), 843-853.

Schmitz, A., Beermann, M., MacKenzie, C. R., Fetz, K., \& Schulz-Quach, C. (2017). Animal-assisted therapy at a University Centre for Palliative Medicine-a qualitative content analysis of patient records. BMC palliative care, 16(1), 50.

Sirbu, A., Vintila, M., Tisu, L., Stefanut, A.M., Tudorel, O, Maguran, B., Toma, R.A., (2020). Parental Alienation- Development and validation of a behavior anchor scale, Sustainability, vol. 13, 1-18.

Stefanut, A, Vintila, M. (2019). Exploring the depression, anxiety, quality of life and self-efficacy of oncological patients and their caregivers: a literature review. Social Research Reports, 11 (1), 104-116.

Swami, V., Khatib, NAM, Vidal-Mollon, J., Vintila, M., Barron, D., Goian, C., Mayoral, O., Toh, EKL, Tudorel, O. \& Vazirani, S. (2020). Visits to Natural Environments Improve State Body Appreciation: Evidence from Malysia, Romania and Spain, Ecopsychology, vol.12, no1.1.

Swami, V., Barron, D., Vintila, M., Ong, HS, Tudorel, O., Goian, C, Wong, KY, Toh, EKL. (2021), An examination of the higher-order dimensionality and psychometric properties of a Romanian translation of the schizotypal personality questionnaire (SPQ), Current Psychology, 6/4, 1-12.

Utz, R. L. (2014). Walking the dog: The effect of pet ownership on human health and health behaviors. Social Indicators Research, 116(2), 327-339.

Vintila, M., Stefanut, A., Sarbescu, P. Effectiveness of couple psycho-oncological interventions in increasing patients and their partners' adaptation to diseases: a systemic review and meta-analysis. Current Psychology, 41 (10), 1-23. 
Vintila, M., Marklinder, I., Nydahl, M., Istrat, D., Kuglis, a., (2009), Health awareness and behaviour of the elderly: between needs and relaity. A comparative study, Revista de Psihologie Aplicata, 11(2), 81-87.

Waite, T. C., Hamilton, L., \& O'Brien, W. (2018). A meta-analysis of animal assisted interventions targeting pain, anxiety and distress in medical settings. Complementary therapies in clinical practice, 33, 49-55. 